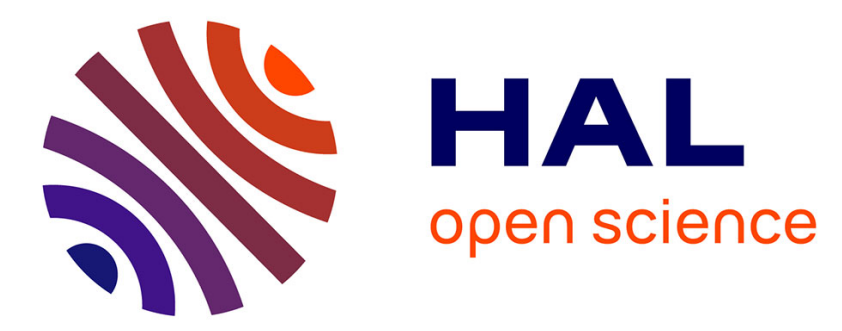

\title{
Electro-mechanical system control based on observers
} Syrine Derbel, Nabih Feki, Jean Pierre Barbot, Florentina Nicolau, Mohamed Abbes, Mohamed Haddar

\section{To cite this version:}

Syrine Derbel, Nabih Feki, Jean Pierre Barbot, Florentina Nicolau, Mohamed Abbes, et al.. Electromechanical system control based on observers. International Conference on Acoustics and Vibration, Mar 2018, Hammamet, Tunisia. hal-02014864

\section{HAL Id: hal-02014864 https://hal.science/hal-02014864}

Submitted on 20 Sep 2019

HAL is a multi-disciplinary open access archive for the deposit and dissemination of scientific research documents, whether they are published or not. The documents may come from teaching and research institutions in France or abroad, or from public or private research centers.
L'archive ouverte pluridisciplinaire HAL, est destinée au dépôt et à la diffusion de documents scientifiques de niveau recherche, publiés ou non, émanant des établissements d'enseignement et de recherche français ou étrangers, des laboratoires publics ou privés. 


\title{
Electro-mechanical system control based on observers
}

\author{
Syrine Derbel ${ }^{1,2}$, Nabih Feki ${ }^{2}$, Jean Pierre Barbot ${ }^{1}$, Florentina Nicolau ${ }^{1}$, \\ Mohamed Slim Abbes ${ }^{2}$, and Mohamed Haddar ${ }^{2}$ \\ 1 Quartz Laboratory / ENSEA, Cergy, France 95014, \\ syrina.derbel@hotmail.fr, \\ ${ }^{2}$ LA2MP Laboratory / ENIS, Sfax, Tunisia 3038
}

\begin{abstract}
The monitoring of the gear behavior is becoming major concerns in several industries for improve production and safety. For this reason, in this article, an electromechanical modeling is developed in order to simulate a gear element driven by an asynchronous motor. The electrical part, which is an induction motor, is modeled by using the Kron's model while the mechanical part, which is a single stage gear element, is accounted for by a torsional model. The mechanical model that simulates the pinion-gear pair is obtained by reducing the degree of freedom of the global spur or helical gear system. The electrical and mechanical state variables are coupling in order to obtain a unique differential system that describes the dynamics of the elecromechanical system. The global coupled electro-mechanical model can be characterized by a unique set of non-linear state equation. The aim of this work is to apply the control based on observers in order to supervise the electrical and mechanical behavior of the electro-mechanical system from only its inputs and its measurements outputs (sensors outputs).
\end{abstract}

Keywords: Gears transmission, Observers, Simulation, Asynchronous motor

\section{Introduction}

Electro-mechanical systems such as mechanical gear transmission driven by induction motors are commonly used in many industrial applications. For this reason, many techniques and tools of control and diagnostics, such as vibration and sound signal analysis (Baydar \& Ball 2001, Tan et al. 2007), analysis of stator currents (Feki 2012), have traditionally been used to supervise the gear element behavior and to detect faults (Chaari et al. 2008). These techniques are advantageous by their reduced cost and present a high reliability. However, they are sensitive to the positioning of the sensors and in some applications, they present technical difficulties to implement sensors in rotating parts or hostile environment. Although gear monitoring by vibration signal analysis and current stator analysis are still widely used, a new method of electro-mechnical system control and monitoring based on observers will be presented in this paper.

In general, for technical and economic reasons, the state of the system is not completely accessible. Indeed, the complexity of the technical feasibility as well as prohibitive costs for the implantation of several sensors can considerably 
reduce the number of states measured. In this case, the state vector size is greater than the output vector size. However, under some conditions of existence, the state can be reconstructed using an observer Larroque (2008).

The paper will be organized as follows: a) in section 2 , a single stage gear element is accounted for by using torsional model, b) in section 3, an electrical modeling of the induction motor is presented, c) the electro-mechnical coupling is developed in section $4, \mathrm{~d}$ ) the section 5 is dedicated to implement the used observer and e) the simulation results of the electro-mechanical system dynamic behavior are presented in section 6 .

\section{Mechanical modeling}

The modeling of the mechanical part (see Fig.1) contains only the gear element. To do this, we are based on the modeling in (Feki et al. 2012) but reduce the global model of 36 degrees of freedom to 2 degrees of freedom. A driving torque

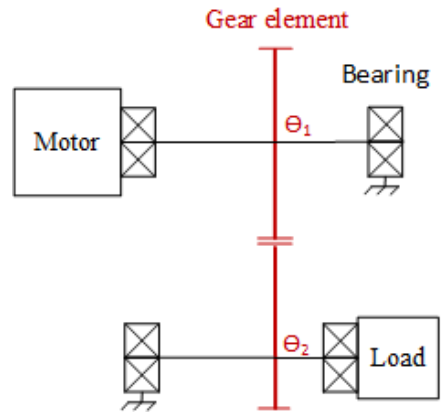

Fig. 1: Electro-mechanical system

$C_{m}$ is applied to the pinion gear and a load torque $C_{r}$ is applied to the wheel gear (attached to output shaft). The system modeling is accounted for by two degrees of freedom, which correspond to the torsional components. Using Euler-Lagrange equation, the motion equation of the torsional model of the gear element is obtained as follows (1):

$$
M \ddot{x}+C \dot{x}+K(t, x) x=F,
$$

where

- $M$ : is the mass matrix composed by the polar moment of inertia for the gear $k$,

- $K(t, x)$ : is stiffness matrix that depends on the state vector and on the time,

- $C$ : is the Rayleigh model damping,

- $F=\left[\begin{array}{ll}C_{m} & C_{r}\end{array}\right]^{t} \in \mathbb{R}^{2}$ : external forces, 
- $x=\left[\begin{array}{ll}\theta_{1} & \theta_{2}\end{array}\right]^{t} \in \mathbb{R}^{2}$ : represents the two degrees of freedom vector.

The stiffness matrix can be expressed in terms of a structural vector $V\left(M_{i}\right)$ (Maatar \& Velex 1996) by using the following form $K(t, x)=k(t) V\left(M_{i}\right) V\left(M_{i}\right)^{t}$, with $k(t)$ the stiffness simulated by a square waveform. Developing (1), we obtain the space representation of the gear element:

$$
\left[\begin{array}{c}
\dot{x} \\
\ddot{x}
\end{array}\right]=\left[\begin{array}{cc}
0 & I_{d} \\
-M^{-1} K-M^{-1} C
\end{array}\right]\left[\begin{array}{l}
x \\
\dot{x}
\end{array}\right]+\left[\begin{array}{c}
0 \\
M^{-1} F
\end{array}\right],
$$

with $I_{d}$ the 2 nd order identity matrix.

\section{$3 \quad$ Electrical modeling}

The motor equations are obtained by using the Kron's transformation model. The key idea of this transformation is to translate the three-phases quantities $(a b c)$ of the motor to an equivalent two-phases quantities (see Fig.2).

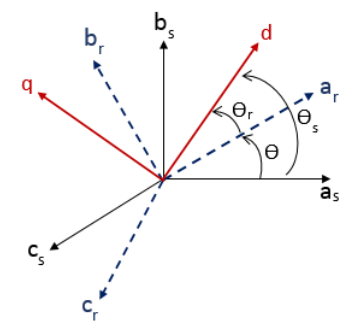

Fig. 2: Park transformation plan.

The stator variables are obtained by $\theta=\theta_{s}=w_{s} t=\left(a_{s}, d\right)$ while the rotor variables are calculated by $\theta=\theta_{r}=\omega_{s l} t=\left(a_{r}, d\right)$.

$$
\begin{aligned}
& {\left[\begin{array}{l}
x_{d} \\
x_{q} \\
x_{0}
\end{array}\right]=T_{2 / 3}\left(\theta_{s}\right)\left[\begin{array}{l}
x_{a} \\
x_{b} \\
x_{c}
\end{array}\right],} \\
& {\left[\begin{array}{l}
x_{d} \\
x_{q} \\
x_{0}
\end{array}\right]=T_{2 / 3}\left(\theta_{r}\right)\left[\begin{array}{l}
x_{a} \\
x_{b} \\
x_{c}
\end{array}\right] .}
\end{aligned}
$$

The voltage equations of the three stator and rotor phases are given by (5) and (6).

$$
\left[\begin{array}{l}
v_{a s} \\
v_{b s} \\
v_{c s}
\end{array}\right]=\left[\begin{array}{ccc}
R_{s} & 0 & 0 \\
0 & R_{s} & 0 \\
0 & 0 & R_{s}
\end{array}\right]\left[\begin{array}{l}
i_{a s} \\
i_{b s} \\
i_{c s}
\end{array}\right]+\frac{d}{d t}\left[\begin{array}{l}
\phi_{a s} \\
\phi_{b s} \\
\phi_{c s}
\end{array}\right],
$$




$$
\left[\begin{array}{l}
v_{a r} \\
v_{b r} \\
v_{c r}
\end{array}\right]=\left[\begin{array}{ccc}
R_{r} & 0 & 0 \\
0 & R_{r} & 0 \\
0 & 0 & R_{r}
\end{array}\right]\left[\begin{array}{c}
i_{a r} \\
i_{b r} \\
i_{c r}
\end{array}\right]+\frac{d}{d t}\left[\begin{array}{l}
\phi_{a r} \\
\phi_{b r} \\
\phi_{c r}
\end{array}\right] .
$$

The flux equations can be written as follows:

$$
\begin{aligned}
& {\left[\phi_{a b c s}\right]=L_{s s}\left[i_{a b c s}\right]+L_{s r}\left[i_{a b c r}\right],} \\
& {\left[\phi_{a b c r}\right]=L_{r r}\left[i_{a b c r}\right]+L_{r s}\left[i_{a b c s}\right],}
\end{aligned}
$$

where

$$
\begin{aligned}
& -L_{s s}=\left[\begin{array}{ccc}
l_{s} & m_{s} & m_{s} \\
m_{s} & l_{s} & m_{s} \\
m_{s} & m_{s} & l_{s}
\end{array}\right]: \text { stator inductance matrix } \\
& -L_{r r}=\left[\begin{array}{ccc}
l_{r} & m_{r} & m_{r} \\
m_{r} & l_{r} & m_{r} \\
m_{r} & m_{r} & l_{r}
\end{array}\right]: \text { rotor inductance matrix } \\
& -L_{s r}=L_{r s}^{t}=m_{s r}\left[\begin{array}{ccc}
\cos (\theta) & \cos \left(\theta+\frac{2 \Pi}{3}\right) & \cos \left(\theta-\frac{2 \Pi}{3}\right) \\
\cos \left(\theta+\frac{2 \Pi}{3}\right) & \cos (\theta) & \cos \left(\theta+\frac{2 \Pi}{3}\right) \\
\cos \left(\theta+\frac{2 \Pi}{3}\right) & \cos \left(\theta-\frac{2 \Pi}{3}\right) & \cos (\theta)
\end{array}\right]: \text { mutual induc- }
\end{aligned}
$$

tance matrix between stator and rotor,

with the constants parameters:

- $l_{s}$ (respectively $l_{r}$ ): self-inductance of the stator (rotor),

- $m_{s}$ (respectively $m_{r}$ ): mutual-inductance between the stator phases (the rotor phases),

- $m_{s r}$ : the maximum value of mutual inductances between stator and rotor phases.

Applying the Kron's transformation for (5),(6),(7) and (8), we obtain:

$$
\begin{gathered}
\left\{\begin{array}{l}
v_{d s}=R_{s} i_{d s}+\frac{d}{d t} \phi_{d s}-\omega_{s} \phi_{d s}, \\
v_{q s}=R_{s} i_{q s}+\frac{d}{d t} \phi_{q s}+\omega_{s} \phi_{q s},
\end{array}\right. \\
\left\{\begin{array}{l}
v_{d r}=R_{r} i_{d r}+\frac{d}{d t} \phi_{d r}-\omega_{s l} \phi_{d r}=0, \\
v_{q r}=R_{r} i_{q r}+\frac{d}{d t} \phi_{q r}+\omega_{s l} \phi_{q r}=0,
\end{array}\right. \\
\left\{\begin{array}{l}
\phi_{d s}=L_{s} i_{d s}+L_{m} i_{d r}, \\
\phi_{q s}=L_{s} i_{q s}+L_{m} i_{q r},
\end{array}\right. \\
\left\{\begin{array}{l}
\phi_{d r}=L_{r} i_{d r}+L_{m} i_{d s}, \\
\phi_{q r}=L_{r} i_{q r}+L_{m} i_{q s},
\end{array}\right.
\end{gathered}
$$

where $L_{s}$ (respectively, $L_{r}$ ) represents the stator synchronous inductance ( respectively, rotor synchronous inductance) and $L_{m}$ is the magnetizing (synchronous) inductance. The advantage of this transformation is the fact that we get a constant mutual inductance and that along an axis, the fluxes depend only to the rotor and stator currents. Relations (9) and (10) detail the electro-magnetic 
behavior of the asynchronous machine written in non a linear differential equations form. These equations can be described in matrix space representation by choosing the space vector $z(t)$ composed by the both stator currents and the both rotor fluxes of the motor:

$$
\dot{z}(t)=A z(t)+B U(t)
$$

with $z(t)=\left[\begin{array}{llll}i_{d s} & i_{q s} & \phi_{d r} & \phi_{q r}\end{array}\right]^{t} \in \mathbb{R}^{4}, U(t)=\left[\begin{array}{ll}v_{d s} & v_{q s}\end{array}\right]^{t} \in \mathbb{R}^{2}$ : the input vector, $A, B$ the state, input matrices given by:

$$
\begin{gathered}
A=\left[\begin{array}{cccc}
-\left(\frac{1}{T_{s} \sigma}+\frac{1}{T_{r}} \frac{1-\sigma}{\sigma}\right) & \omega_{s} & \frac{1-\sigma}{\sigma} \frac{1}{L_{m} T_{r}} & \frac{1-\sigma}{\sigma} \frac{\omega_{m}}{L_{m}} \\
-\omega_{s} & -\left(\frac{1}{T_{s} \sigma}+\frac{1}{T_{r}} \frac{1-\sigma}{\sigma}\right) & -\frac{1-\sigma}{\sigma} \frac{\omega_{m}}{L_{m}} & \frac{1-\sigma}{\sigma} \frac{1}{L_{m} T_{r}} \\
\frac{L_{m}}{T_{r}} & 0 & -\frac{1}{T_{r}} & w_{s l} \\
0 & & -w_{s l} & -\frac{1}{T_{r}}
\end{array}\right], \\
B=\left[\begin{array}{cc}
\frac{1}{\sigma L_{r}} & 0 \\
0 & \frac{1}{\sigma L_{s}} \\
0 & 0 \\
0 & 0
\end{array}\right],
\end{gathered}
$$

where the constants parameters are explained below:

$$
-\sigma=1-\frac{L_{m}^{2}}{L_{s} L_{r}}, \quad T_{s}=\frac{L_{s}}{R_{s}}, \quad T_{r}=\frac{L_{r}}{R_{r}} .
$$

The electromagnetic torque is represented by (16), with $p$ the number of polepairs.

$$
C_{e m}=\frac{p L_{m}}{L_{r}}\left(\phi_{d r} i_{q s}-\phi_{q r} i_{d s}\right) .
$$

\section{Electro-mechanical coupling}

The aim of the electro-mechanical coupling is to obtain a space representation that includes the mechanical system with two degrees of freedom and the induction motor equations (see Fig.1). This modeling allows to implement control methods to supervise the dynamic behavior of the system. The electro-magnetic torque given by (16) is regarded as the input of the mechanical part and the small vibrations caused by the gear element act on the speed rotation of the asynchronous motor. The coupled system leads to a first order differential system of the form:

$$
\dot{\zeta}(t)=A_{c}(t, \zeta) \zeta(t)+G u,
$$

where $\zeta(t)=\left[\begin{array}{llllllll}i_{d s} & i_{q s} & \phi_{d r} & \phi_{q r} & \theta_{1} & \theta_{2} & \dot{\theta}_{1} & \dot{\theta}_{2}\end{array}\right]^{t}$ : the global state vector, $A_{c}=\left[\begin{array}{ll}A & 0 \\ P & H\end{array}\right]$ is the state matrix, with $A$ the state matrix associated to the 
electric part expressed in (14), $P \in \mathbb{R}^{(4 \times 4)}$ is the coupling matrix between the electric and mechanical part depending to the electromagnetic torque donated by (16) and $H=\left[\begin{array}{cccc}0 & 0 & 1 & 0 \\ 0 & 0 & 0 & 1 \\ -M^{-1} K & -M^{-1} C\end{array}\right]$ is the matrix associated to the gear modeling $G=\left[\begin{array}{cccc}\frac{1}{\sigma L_{s}} & 0 & 0 & 0 \\ 0 & \frac{1}{\sigma L_{s}} & 0 & 0 \\ 0 & 0 & 0 & 0 \\ 0 & 0 & 0 & 0 \\ 0 & 0 & 1 & 0 \\ 0 & 0 & 0 & 1 \\ 0 & 0 & \\ 0 & 0 & \end{array}\right]$ is the input matrix and $u=\left[\begin{array}{c}v_{d s} \\ v_{q s} \\ 0 \\ C_{r}\end{array}\right]$ the input vector.

The evolution of the system is obtained by introducing the control based on observers to monitor the dynamic behavior of the electro-mechanical system.

\section{Observer form}

A state observer is a control method (Perruquetti \& Barbot 2002) that gives an estimate of the internal state of the real system, only from the measurements given by the sensors and the real input of the system. The observers are used in order to control the behavior of systems, to detect the faults or to identify the unknown parameters of systems (Oueder 2012). In our case, four differentiatiors (Ghanes et al. 2017) are used to estimate the drift of both currents of the asynchronous motor and the displacements of the gear element. Assuming that $\left[s_{1}, \ldots, s_{8}\right]=\left[i_{d s}, \dot{i}_{d s}, i_{q s}, \dot{i}_{q s}, \theta_{1}, \dot{\theta}_{1}, \theta_{2}, \dot{\theta}_{2}\right]$, the observer equations are written in following form:

$$
\left\{\begin{array}{l}
\dot{\hat{s}}_{i}=\hat{s}_{i+1}+k_{1} \mu_{j}\left|e_{i}\right|^{\alpha} \operatorname{sign}\left(e_{i}\right) \\
\dot{\hat{s}}_{i+1}=k_{2} \alpha \mu_{j}{ }^{2}\left|e_{i}\right|^{2 \alpha-1} \operatorname{sign}\left(e_{i}\right) \\
e_{i}=s_{i}-\hat{s}_{i}
\end{array}\right.
$$

where

- $e_{i}, i=\{1,3,5,7\}$ are the output estimation errors,

$-k_{1}, k_{2}$ are constants acting on the stability of the system,

$-\mu_{j}, j=1,2$ are positive constants, the first one associated to the electric model and the second one is related to the mechanical part.

\section{Simulation and Results}

In this simulation, a spur gear system is considered. The main characteristics of the gear are given in table 1 and the motor parameters are shown in table 2. 
Table 1: Gears parameters

\begin{tabular}{cc}
\hline Parameters & value \\
\hline Module (mm) & 4 \\
Tooth number of Pinion & 21 \\
Tooth number of wheel & 31 \\
Face width (mm) & 10 \\
Pressure angle & 20 \\
\hline
\end{tabular}

Table 2: Electric parameters

\begin{tabular}{cc}
\hline Parameters & value \\
\hline Stator resistance $R_{s}(\Omega)$ & 9.163 \\
Rotor resistance $R_{r}(\Omega)$ & 5.398 \\
Stator inductance $L_{s}(\mathrm{H})$ & 0.115 \\
Rotor inductance $L_{r}(\mathrm{H})$ & 0.0943 \\
Magnetizing inductance $L_{m}(\mathrm{H})$ & 0.0943 \\
Number of pole-pairs $p$ & 1 \\
\hline
\end{tabular}

As it can be noticed, the applied observer gives a good performances (see Fig .3, 4, 5 and 6). In these figures, the estimated states converge, in finite time, to the real quantities states. Fig .3 and Fig. 4 represent the two stator currents expressed in $(d q 0)$ frame. They show that the periodic recurrence of gears meshing frequency $t_{m}$ is regained in the electrical states.

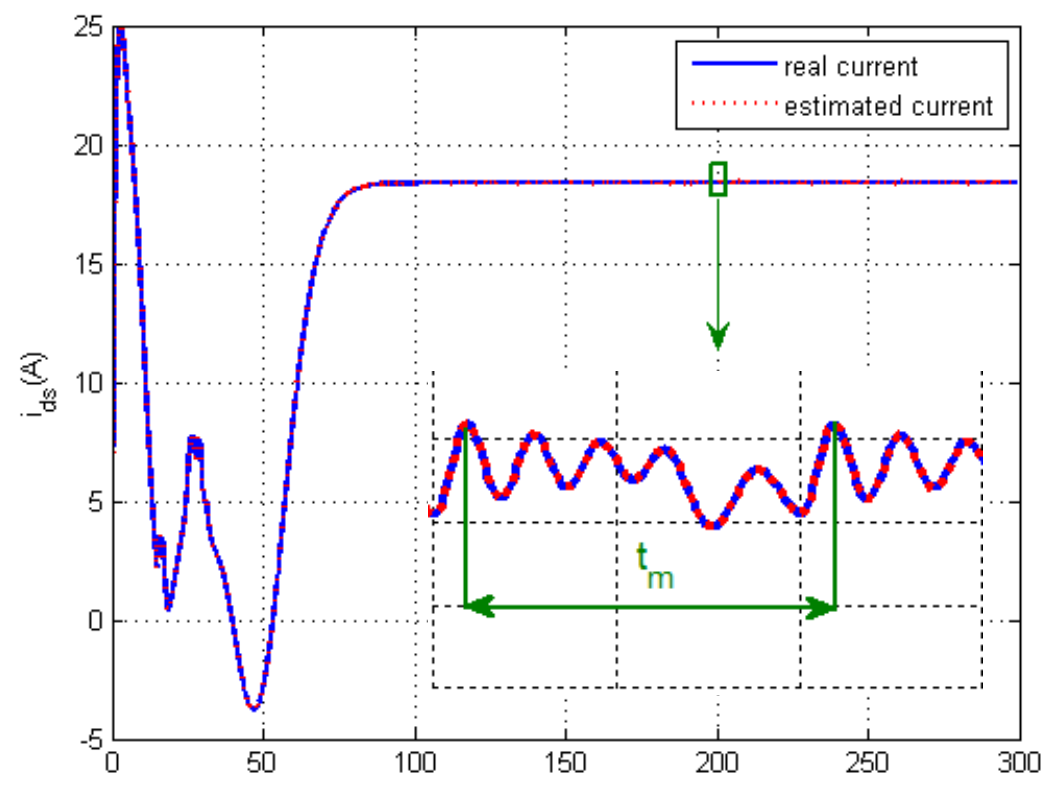

Fig. 3: State $\zeta_{1}$ and its estimate 


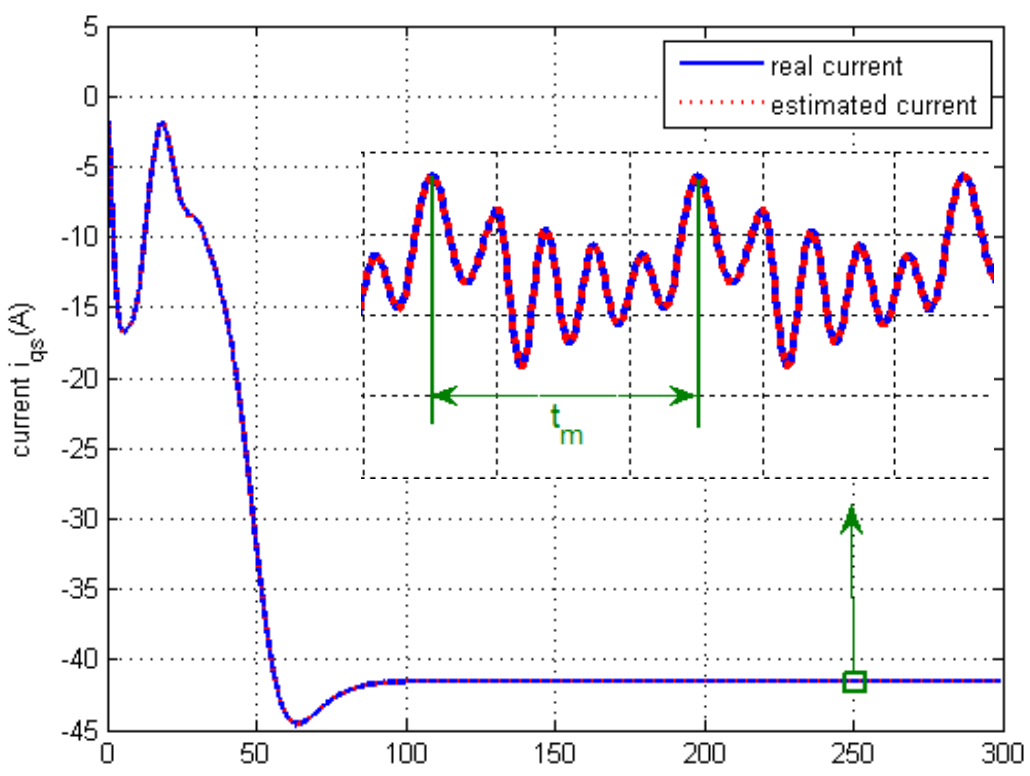

Fig. 4: State $\zeta_{2}$ and its estimate

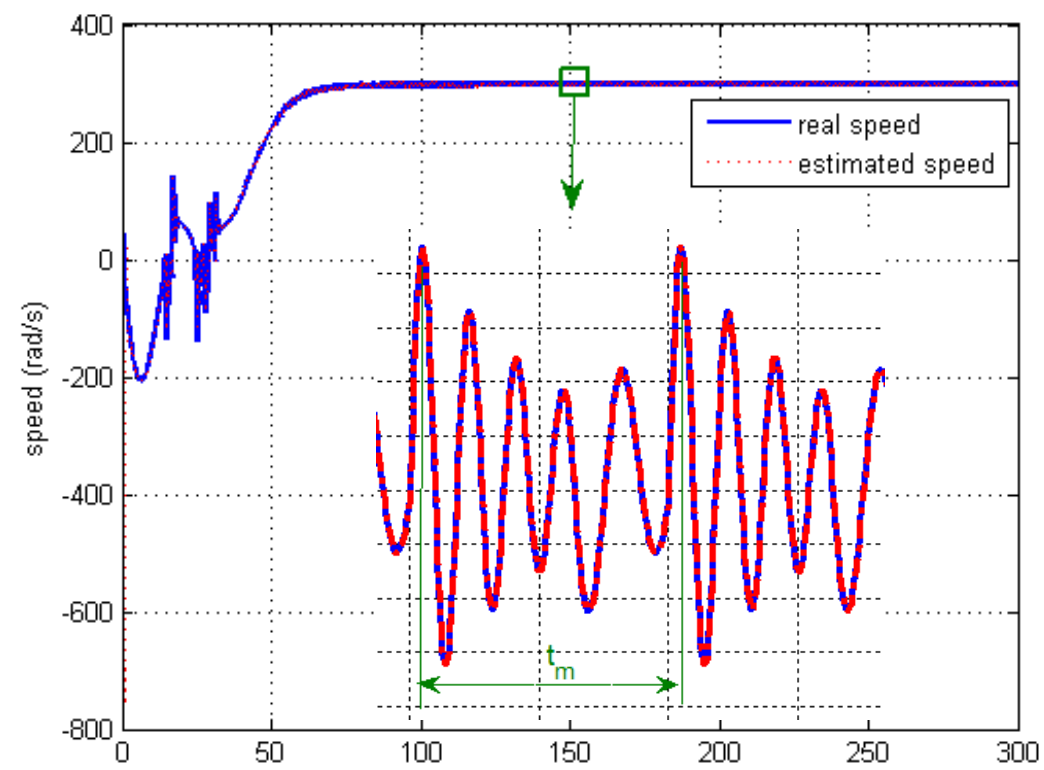

Fig. 5: State $\zeta_{7}$ and its estimate 
Fig. 5 illustrates that the rotational speed of the pinion is of the order to $300 \mathrm{rad} / \mathrm{s}$. This value represents the average meshing speed added to the small vibrations of the gear.

The last figure (Fig. 6) displays the evolution of the error transmission given by the equation $R_{b 1} \theta_{1}+R_{b 2} \theta_{2}$ (where $R_{b 1}, R_{b 2}$ are, respectively, the base radii of the pinion and the wheel).

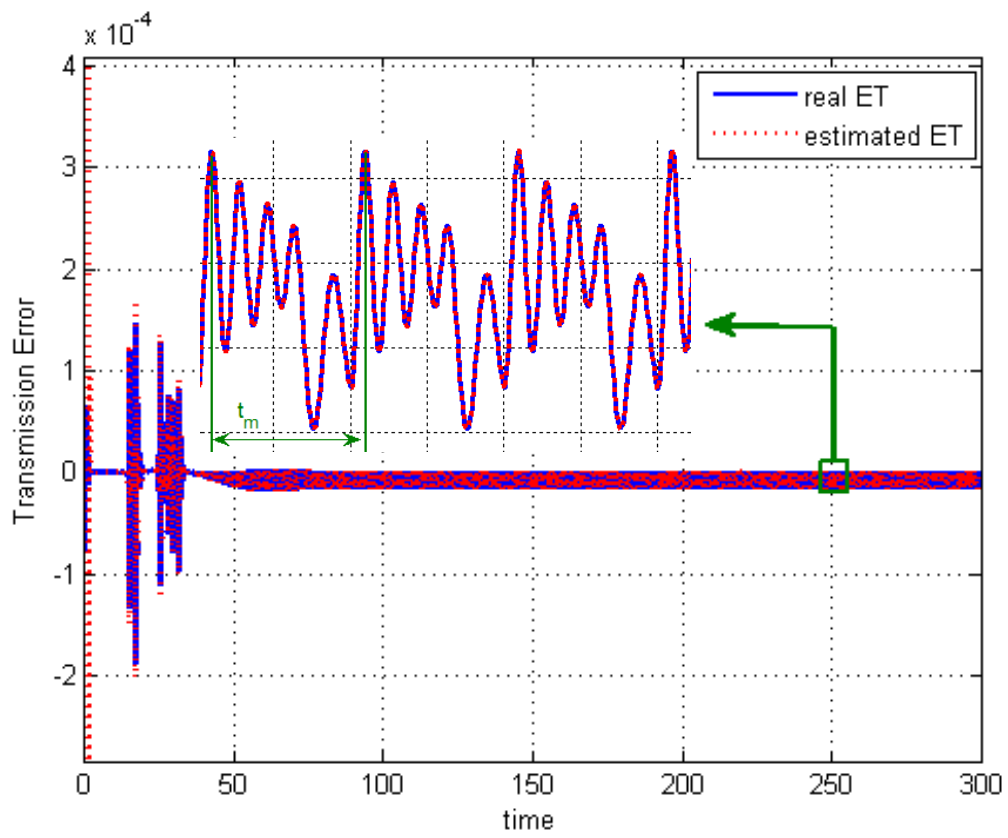

Fig. 6: Real and estimated transmission error

All results confirm the good convergence of the applied observer. This convergence has appeared in the frequency content and the amplitude of the electromechanical system behavior signals. Meaning that the evolution of the real states and those of the estimated quantities are perfectly confused in the frequency study. The observer gives a rapid and accurate convergence for all system states.

\section{Conclusion}

In this paper, an electro-mechanical coupling of the gear transmission system driven by a asynchronous motor has been studied. The monitoring of this model is obtained by using the control based on observers. Further work is in progress in order to implement other types of observers with presence of gear faults and variation of the sensors noise. 


\section{Bibliography}

Baydar, N. \& Ball, A. (2001), 'A comparative study of acoustic and vibration signals in detection of gear failures using wigner-ville distribution', Mechanical Systems and Signal Processing 15, 1091-1107.

Chaari, F., Baccar, W., Abbes, M. S. \& Haddar, M. (2008), 'Effect of spalling or tooth breakage on gearmesh stiffness and dynamic response of a one-stage spur gear transmission', European Journal of Mechanics-A/Solids 27(4), 691-705.

Feki, N. (2012), Modelisation electro-mecanique de transmissions par engrenages : Applications à la detection et au suivi des avaries, $\mathrm{PhD}$ thesis. These de doctorat dirigée par Clerc, Guy et Velex, Philippe Mécanique Lyon, INSA 2012.

URL: http://www.theses.fr/2012ISAL0041/document

Feki, N., Clerc, G. \& Velex, P. (2012), 'An integrated electro-mechanical model of motor-gear units?applications to tooth fault detection by electric measurements', Mechanical Systems and Signal Processing 29, 377-390.

Ghanes, M., Barbot, J.-P., Fridman, L. \& Levant, A. (2017), A second order sliding mode differentiator with a variable exponent, in 'American Control Conference (ACC), 2017', IEEE, pp. 3300-3305.

Larroque, B. (2008), Observateurs de systémes linéaires: application à la détection et localisation de fautes, PhD thesis, Institut National Polytechnique de Toulouse.

Maatar, M. \& Velex, P. (1996), 'An analytical expression for the time-varying contact length in perfect cylindrical gears: some possible applications in gear dynamics', Transactions of the ASME-R-Journal of Mechanical Design 118(4), 586-588.

Oueder, M. (2012), Synthese des observateurs pour les systemes non linéaires, $\mathrm{PhD}$ thesis, Université de Caen.

Perruquetti, W. \& Barbot, J.-P. (2002), Sliding mode control in engineering, CRC Press.

Tan, C. K., Irving, P. \& Mba, D. (2007), 'A comparative experimental study on the diagnostic and prognostic capabilities of acoustics emission, vibration and spectrometric oil analysis for spur gears', Mechanical Systems and Signal Processing 21(1), 208-233. 